To cite this article:

Green C (2013) Relative Distancing: A grounded theory of how learners negotiate the interprofessional. Journal of Interprofessional Care, 27: 34-42. doi:

10.3109/13561820.2012.720313

To link to this article: http://dx.doi.org/10.3109/13561820.2012.720313

\title{
Relative Distancing: a grounded theory of how learners negotiate the interprofessional
}

Keywords: IPE, grounded theory, relative distancing, efficiency, identity.

\begin{abstract}
A number of extant educational, psychological and sociological theories have been suggested as possessing utility for interprofessional education (IPE). However, there is limited theory proposed that has been derived directly from data. This article adds to the theoretical toolkit by theorising from data using constructionist grounded theorising.
\end{abstract}

This article discusses the grounded theorising of participants' approaches to IPE and describes the social process of relative distancing, a collection of strategies employed by participants to construct their own professional identities and negotiate their way through interprofessional interactions. The categories of relative distancing are conceptualised as 1) integrating the professional and the interprofessional; 2) constellating and maintaining distance; 3) tensioning and manipulating distance; and 4) the dimensions of distance. The first, and most theoretically integrative, category will be discussed in detail here. 
It was found that participants valued certain learning outcomes over others. They favoured learning opportunities that were perceived to be of direct relevance to their own professional development and contributed finite personal resources to these. Resources were committed to those interprofessional learning opportunities where relevance was perceived and the conditions of co-presence (with other professions) and a context for interaction were achieved. The discussion draws links between the data and contemporary discourses of economics and identity.

\section{Introduction}

Conceptual and practical work to define and design the "interprofessional" has dramatically gathered pace in the first decade of the twenty-first century, though such activities have their roots in the embryonic interprofessional arena of the 1960s. Educationalists, practitioners, service providers, researchers and commentators have made attempts "to define terms, unravel semantics, develop rationale, refine methodologies for evaluation and secure evidence" (Barr, 2002, p.6). Furthermore, determining theoretical perspectives to guide implementation of interprofessional education (IPE) has been afforded much greater prominence in recent years (e.g. D’Eon, 2005; Clark, 2006; Reeves et al., 2007; Hean et al., 2008; Hean, Craddock \& O'Halloran, 2009; Hean, Craddock \& Hammick, 2012). The main objective of this work has been to foster the credibility of IPE and collaborative practice as discrete concepts amongst academe (Barr \& Ross, 2006), drawing primarily upon extant theoretical frames provided from a variety of sub-disciplines of education, psychology and, to some extent, sociology. These frames have been sought to give a theoretical foothold to the praxis of designing, delivering and evaluating IPE. 
There has been considerably less progress made, however, in the generation of new theoretical formulations from empirical data. Also, methodological applications have tended to favour a modernist framing that befits the dominant philosophical trends of the disciplinary roots from which extant theories have been drawn. In a previous editorial of this Journal, Reeves (2010, p.218) recognises that there is significant work to be done both empirically and theoretically to advance and inform the "undertheorised" interprofessional arena. He acknowledges the scarcity in representation of sociological perspectives and qualitative work, suggesting that such perspectives can provide "some much needed critical framing of interprofessional activities to understand how micro-interactions between professions are enacted within larger political, social and economic structures". This article presents a data-derived conceptual framing of IPE using grounded theorising that, to some extent, provides a sociological representation.

\section{Conceptualising collaboration}

IPE allows individuals from different professional backgrounds to meet, interact and learn together, and has been recommended as a potentially effective means of enhancing collaborative practice and achieving optimal health outcomes. The Framework for Action from the World Health Organisation (WHO, 2010: p.12-13) entrenches these assumptions within a contemporary resource-based discourse:

"Human resources for health are in crisis...Governments around the world are looking for innovative, system-transforming solutions that will ensure the appropriate supply, mix and distribution of the health workforce. One of the most promising solutions can be found in interprofessional collaboration. A greater understanding of how this strategy can be implemented will help WHO Member States build more flexible health 
workforces that enable local health needs to be met while maximising limited resources."

The Framework also represents a recent example of consensus-building in the interprofessional arena, providing an "internationally agreed set of definitions for terms frequently used by the global interprofessional community of practice" (WHO Study Group, 2010). IPE and collaborative practice are almost exclusively conceptualised in terms of individuals (e.g. students, practitioners, service users) as members of collectives (e.g. professions, groups, teams, communities). Concordance in conceptualising IPE and collaborative practice facilitates translation of concepts between settings, but necessarily simplifies the inherent complexity of the interprofessional arena to a linear causal model that assumes that IPE leads to collaboration in practice. Several studies have sought to open up the "black boxes" (Latour, 1987) of IPE and collaborative practice, but few have used inductive theorising to achieve this.

Gilbert and Bainbridge (2003, p.285) emphasise that those committed to theorising IPE need to "turn concepts of IPE from either mystical attitudes of faith, or pragmatic responses to gaps in service, into ideas that can be understood intellectually, challenged experimentally and argued for politically". Some had made attempts to deliver descriptive conceptual frames upon which to hang the design, delivery and evaluation of IPE (e.g. D’Eon, 2005; Freeth, Hammick, Reeves, Koppel \& Barr, 2005; Hean et al., 2008; 2009; 2012), whilst others suggested what form theoretical perspectives might take (e.g. Clark, 2006). This article describes categories developed through the inductive theorising of IPE using data derived from learners and leaders of an interprofessional pre-registration programme. 


\section{Research Design}

This study employed a constructionist grounded theorising approach using analytic techniques described by Charmaz (2006). Blumer's (1969) notion of sensitising concepts aided the development of the research aim: to conceptualise the social processes that constitute activities in IPE and collaborative practice. IPE and collaborative practice may be considered sensitising (though contested) concepts. My research interest involved how students view these concepts in their own terms and how their situated activities shape their views and actions.

\section{Data collection and analysis}

Ethical approval was received from the University Ethics Committee, the NHS Local Research Ethics Committee and the Research and Development office of the NHS Trust where participant observation was conducted. A purposive sample of students and graduates were recruited from a pre-registration interprofessional Masters level programme. The programme consisted of a mixture of uniprofessional and interprofessional modules. Interprofessional modules used problem-based scenario groups and seminars to promote applied interprofessional learning. Informed consent was gained from twenty-eight participants (five recent graduates and twentythree students). Semi-structured interviews (Holstein \& Gubrium, 2003; Charmaz, 2006) were conducted with these participants who represented adult nursing (8), mental health nursing (6), physiotherapy (4) and speech and language therapy (10). Data collection, analysis and theoretical sampling occurred concurrently so that new sources of theoretically important data could be identified and located whilst analysis remained on-going. Grounded theorising does not aim to represent a given 
population, but strives for theoretical sufficiency (Dey, 1999; Clarke, 2005). Theoretical sampling is a distinctive feature of grounded theorising as further data sources are selected based on the emergent conceptual analysis (Glaser \& Strauss, 1967). Following early analysis, it became clear that experiences learners had in practice placements and interactions they had with programme lead lecturers were influential in students' meaning-making. This informed the theoretical sampling of interviews with two interprofessional programme leads, participant observation conducted in two ward settings on six clinical shifts over a two-week period (Spradley, 1980; Timmermans \& Tavory, 2007) and the use of participant reflective diaries (Zimmermann \& Wieder, 1977; Benner, 1984).

Interview transcripts, reflective diaries and observational field notes were analysed using initial and focused coding, memoing and constant comparison (Charmaz, 2006). Initial coding remained open and preliminary, focused coding became more selective as concepts developed and categories became densified. During initial coding, the following questions were considered:

- What is this data a study of? (Glaser, 1978, p.57; Charmaz, 2006)

- What category does this incident indicate? (Glaser, 1998, p.123; Charmaz, 2006).

- Whose point of view does this data represent? (Clarke, 2005; Charmaz, 2006).

During focused coding, preliminary concepts were used to sift through data to identify the properties of emergent categories. The concept of distancing emerged after analysis of the third interview and was selected as conceptually integrative after 
analysis of the twenty-third interview. Memo writing aided the formulation of ideas and drew links between concepts. Further comparisons between data, codes, memos and emergent categories upped the level of conceptualisation and allowed relative distancing to become densified, integrating other emergent categories (Glaser, 2005; Charmaz, 2006).

\section{Relative Distancing in IPE}

Relative distancing conceptualises the social processes that emerged in the dataset. It represents the strategies participants employ to construct their own professional identities and negotiate their way through interprofessional interactions. Distance between self and others is maintained to privilege and protect professional outcomes that possess perceived value to the individual. Participants' decision-making is continually directed by a functional economic choice concerning where and how to devote finite personal resources. Participants apportion value to specific outcomes and weigh up the worth of devoting resources to these. This allows participants to constellate, maintain and manipulate distances between themselves and others. The agency of the non-human - space, materials, hierarchy, allegiance and discourse - also acts to maintain relative distance controlling the extent to which interactions and collaborations can reasonably occur.

Relative distancing is constituted by four inter-related categories:

1. Integrating the professional and the interprofessional;

2. Constellating and maintaining distance;

3. Tensioning and manipulating distance;

4. The dimensions of distance. 
For the purposes of this article the first category, integrating the professional and the interprofessional, will be discussed in details using illustrative extracts from the data. This category was the most theoretically integrative, underpinning participants' decision-making and indicating immersion in discourses that emphasise economic efficiency and prudence. The second, third and fourth categories will be briefly summarised to enable coverage of theoretical developments.

\section{Integrating the professional and the interprofessional}

"Integrating the professional and the interprofessional" demonstrates how the interprofessional could be alternatively constructed as a dimension of the professional, or as additional to the professional. The first alternative represents integration of the professional and interprofessional whilst the second emphasises selectivity - that "being interprofessional" is an option rather than a requirement of "being professional". Participants made comparisons between their own and other professions, developing and nurturing professional identities vis-à-vis these others. The extent to which they were prepared to devote finite resources to those outcomes they recognised as interprofessional (specifically IPE) was decided based upon how relevant the interprofessional was perceived to be. This process of integration was functional - it served the purpose of classifying for participants whether involvement in certain activities and interactions was "worth the investment" with regard to a valued return.

\section{Efficiency, Value and Worth}


Participants delivered stories about levels of commitment to learning; and how their level of commitment varied in terms of the value that different learning opportunities held for participants.

"...I value it [this term's interprofessional module] more this term...because for me there is less work involved...last term we had to spend time...and feedback..." (Speech and Language Therapy, First Year student; 2007D)

This participant actively compares one interprofessional module of the programme with another, stating that value is apportioned through such comparing. The participant constructs "time" as a personal resource that was used up in producing feedback. Through comparison with other data from other participants, "time" emerged as the most important and finite personal resource; other resources (e.g. energy, money, materials) were also identified, albeit less often, and the worth of investing these resources in varying endeavours was considered by participants:

\begin{abstract}
"When we first started the [interprofessional] groups I used to make copious notes for feedback, pages and pages of it. Some others did too...but some didn't really make the effort...I mean why should I go to all that effort on my feedback to the group when others aren't pulling their weight as much? Now I just focus on the pertinent points and devote my energies to getting my essays written." (Mental Health Nursing, Second Year student; 1306B)

"... We're told that the more we put in the more we get out of it. Whilst that's true for the bit of the work you do for your feedback, it's not the same...Unless others make the same effort, you end-up short-changed." (Physiotherapy, First Year student; 0707C)
\end{abstract}

Here, participants are constructing the worth of investing time and energy in to interprofessional group work, based upon the reciprocal feedback they receive from other members of their group. In this sense, the interprofessional group is constructed as a marketplace where feedback is bartered and exchanged between individuals and professions. Specifically, being "short-changed" indicated the perception of an unequal exchange where personal effort was not equally reciprocated. 
Theoretically-sampled data from programme leads again provided powerful examples of an immersion in a resource-focused discourse. In this extract, "time" is again constructed as a finite resource which has "to be invested" in achieving one outcome (i.e. paperwork for regulatory review) at the detriment of achieving an alternative valued outcome (i.e. enhancing the "interprofessional working" on the programme):

"...I think there's lots more we can do in terms of interprofessional working particularly...I think we have far more opportunity to do that if we didn't have so many checks [from regulatory bodies] every year...And there's a lot of work, paperwork associated with that which you have to invest some of this time in to...." (Programme Lead 1, my emphasis)

By comparing this example with codes such as "apportioning value", "being shortchanged" and "spending time" the emergence of resources as finite and the strategic choices that had to be made in devoting resources to specific valued outcomes were recognised. In the following extract, another programme lead alludes to this same relationship between worth and value when discussing the early development of the programme:

"Obviously we were on a very short timescale...nobody had been given the time really to develop it...And that is what is disappointing about never having a time frame to build these things up. I mean financially it is just not viable nowadays...But then you can get the whole team...buying into what is going on...we could all have started with a blank sheet...but pragmatically that was a massive time commitment that I am not sure we have got the luxury available to us...." [Programme Lead 2, my emphasis]

The in-vivo code "buying into" implies, yet again, investment of resources in the interprofessional with the result of mutual gains for each profession. Again, this implies balancing the worth of investment against a valued return. 
Data were infused with a repeated relationship between the constructions of value and worth. The value of a particular outcome was balanced against the worth of devoting resources to it. For student participants, the focused code "achieving professional status" was conceptualised as a valued outcome and was accompanied by some expression of focus that would help professional status to be achieved. Participants appeared to be answering the question of "Is it worth it?" with the question "How much do I value it?" Student participants focused upon professional career goals as valued outcomes to be achieved, devoting personal resources to meet these ends. This relationship between value and worth, where worth is calculated as a function of a valued outcome and resources then devoted accordingly, suggested thriftiness amongst participants. Finite resources were not bestowed lavishly; rather participants learnt how best to dedicate resources most economically in order to achieve the outcomes they valued. This prudent relationship between the worth of devoting resources to achieving valued outcomes became categorised as efficiency.

\section{“Them" and "Us": Intra- and interprofessional comparing}

Those incidents in the data where participants made comparisons within a single profession tended to emphasise similarities:

"...in the physio group we're all in the same boat. We all have the same competencies to learn and practice and the same standard to reach in our knowledge and skills." (Physiotherapy, First Year student; 0707C)

Here similarities relate to shared competence - "we all have the same competencies to learn". This emphasis on similar competence was repeated within all the professional groups represented by participants: 
"And I really liked those sessions where we were just with the adult nurses...you could knuckle down to the nitty-gritty of what you do as a nurse" (Adult Nursing, qualified, 0204A)

"I value the speech and language kind of uniprofessional sessions more [than interprofessional ones]....because you can concentrate on the things you need to learn for the job you had chosen...we were all of us training to do the same job" (Speech and Language Therapy, Second Year student, 0206D)

"I have got loads out of my mental health training. I feel prepared because that time spent with the rest of the mental health lot kind of galvanises you...I thought the interprofessional modules were useful, but it's the mental health stuff that makes you a competent mental health nurse..." (Mental Health Nursing, qualified, 0405B)

Participants appeared to demonstrate a taken-for-granted logic that the time spent learning profession-specific competencies enables them to perform their professional role or job. As a result, learning in individual professional groups was often considered more relevant and therefore more valuable so personal resources were more regularly devoted to these. Also, the pronoun "we" was regularly employed to represent one's belonging to a professional group and suggests the nurturing of an emergent professional group identity. The attachment of collective pronouns (such as "we", "us", "they" and "them") indicated how participants related themselves to others, depending on what they were discussing and comparing.

Lines of interprofessional comparison were subtly delineated and context-dependent, with the attachment of collective pronouns and the construction of "distance" based upon the relevance of a specific issue to the individual or profession vis-à-vis another individual or profession. "Possessing relevance" was a fairly common initial code, especially when participants described the components of their interprofessional programme:

"...some of the skills competencies we [the adult nurses] have to do are the same for others. Take manual handling, for example, we did that just as a group of nurses...but that's a skill that's relevant to almost all health professions so why not do it together? When it is relevant to everyone then it does get you working more as a team." (Adult Nursing, qualified, 0304A) 
This participant suggests that components of their course that are taught interprofessionally need to possess relevance for all of those involved. Relevance, it is suggested here, gets "you working more as a team". In this extract the "you" that is "working...as a team" is representing different professions; it is "them and us". If relevance was less apparent to the individual then the distance between "them" and "us" increased:

"With the physios it seemed like it was a little bit too distant from us to be as relevant...like some of the stuff that would come up...was really, really relevant for them. But you'd be sitting there thinking, what's this got to do with what I have got to do though?" (Mental Health Nursing, qualified, 0404B, my emphasis)

Recognition of the way attachments of collective pronouns changed depending on what was discussed led to the first use of the term "distancing" in the analysis. An early analytic memo provisionally titled "professional distance" stated:

"Participants are often distancing themselves. They locate themselves as individuals close to their own professional group. They also locate their profession, as a group, in relation to other professions. The closeness or separateness of this distance depends upon the relevance to them of what it is they are talking about..."

Comparisons made by participants were conceptually integrated using the category label "them" and "us". Whilst this label captured the comparative work that participants were doing, it did not sufficiently explain the conditions that resulted in variations in closeness/separateness. The observation of locating oneself or one's profession relative to others and other professions was conceptualised as relative distancing - with the construction of distance varying from incident to incident. Assimilating the categories "them" and "us" and efficiency facilitated the emergence of the theorised category "Integrating the professional and the 
interprofessional", where relevance was the central condition to the apportioning of value, and therefore personal resources, to interprofessional activities.

Data demonstrated time and again that the application of personal resources was prioritised based upon what participants deemed as relevant to their own professional development. The extract below reiterates the preciousness of time as a resource and the focusing of this resource on "what is important... becoming competent....to the standard of a qualified nurse", suggesting that in this case the interprofessional is seen as additional to the professional:

"Time is really precious on this course so you have to use it wisely. I need to focus on what is important and that is becoming competent...The interprofessional modules could be interesting and all that but...they are distracting too.... a bit of a waste of time sometimes when you need to focus on getting yourself to that standard of a qualified nurse." (Mental Health Nursing, First Year student, 1207B)

When "being interprofessional" was seen as relevant to professional priorities then it was constructed as a dimension of the professional and resources were devoted to interprofessional activities:

"Being a professional, whatever profession it is, is about being interprofessional really, isn't it? We have to work in teams whatever our speciality is...so you can't be one without the other. You can't be a competent professional without being able to learn from others...[and] work together for everyone's benefit." (Adult Nursing, First Year student, 1707A)

"Working together is necessary nowadays...l think the whole course is important...having us all working together...that's how it is out there...we could have done more interprofessional really with more time dedicated to it...it was really good to understand how each profession contributes and that's not something you get from just doing a speech and language [therapy] course." (Speech and Language Therapy, Second Year student, 0606D)

By making comparisons between their own and other professions, participants were developing their own professional identities vis-à-vis others. The extent to which the professional and interprofessional could be integrated was dependent upon how 
relevant the interprofessional was perceived to be. If IPE was perceived as relevant to personal and professional development, and therefore perceived as a valued outcome to be achieved, then resources were devoted accordingly; if not then resources were focused upon alternative professional priorities.

\section{Other categories of relative distancing: a summary}

The second category, constellating and maintaining distance, describes the processes of socialisation experienced by participants in professional and interprofessional learning. Membership of a professional group allowed participants to represent themselves and their profession to others by framing their roles and responsibilities within fairly rigid, habitual and inflexible boundaries:

"we have got a policy...that says exactly what we will do and what we won't do..." (Adult Nursing, qualified, 0604A)

There is evidence, too, of immersion in specific professional discourses that contribute to distancing participants from members of other professions, as well as between professions and service users with whom participants engaged. This enables participants to experience a level of comfort in perceiving relatively stable roles for different professions and service users, thereby constellating and maintaining distance vis-à-vis others. However, maintaining such distances could reduce the extent to which participants could collaboratively engage with both other professionals and service users.

Category three, tensioning and manipulating distance, demonstrates the means by which previously held assumptions, established in constellating and maintaining 
distance, could be reconsidered. It highlights the conditions of co-presence and context for interaction as potentiating tension in participants' perceptions, and how such tension can manipulate distances. Tensioning occasionally occurred in spontaneous and unplanned circumstances, however most incidents of tensioning in the data related to the deliberate manipulation of a situation, such as an IPE activity. Where IPE was seen as relevant, offered co-presence with other professions and allowed a context for meaningful interaction between professions, so participants came to review and manipulate the distances they constructed, further integrating the professional and the interprofessional. IPE was seen as relevant and possessing value when it added a competency to one's professional repertoire; improved academic achievement; or meaningfully and obviously contributed to service user experience. Participants were prepared to commit resources to IPE in order to achieve a valued outcome. If the IPE was not considered relevant then it was not perceived as worth the risk, then fewer resources were devoted in its servitude.

The final category, dimensions of distance, demonstrates how non-human elements influenced the social organisation of IPE experienced by participants, limiting and directing the interactions they could engage in. In this dataset, the physical dimensions of space and materials affected the organisation and distribution of individuals; and the socially discursive dimensions of allegiance and hierarchy affected the extent to which interprofessional interactions could be achieved. Spatial distancing described how environmental and architectural organisation affected the extent to which participants could meaningfully learn and work together; material distancing conceptualised how technology and documentation distributed and 
concentrated professional and interprofessional activity; allegiance distancing describes the way collective commitments are forged based on professional and disciplinary ties within a community of practice; and hierarchical distancing conceptualises the way participants ascribed authority and status to their own and other professions. These influences had consequences for IPE and the extent to which the professional and interprofessional could be integrated. The relationship between the four categories of relative distancing is shown in Figure 1.

Figure 1: Linking the categories of Relative Distancing

The functional influence on the relative distancing process

The Relative Distancing process

The situational influence on the Relative Distancing process
Integrating the professional and the interprofessional

$\downarrow$

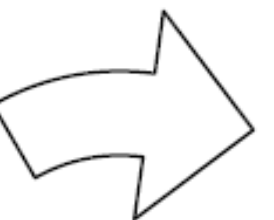

MAINTAINING

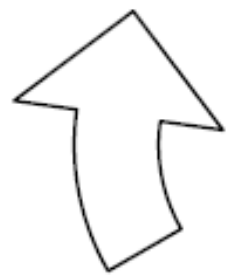

MANIPULATING

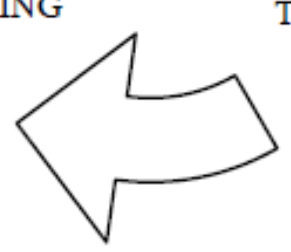

TENSIONING

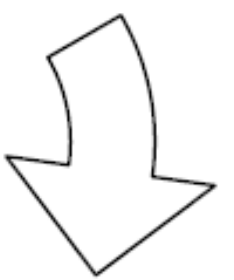

$\uparrow$

Dimensions:

Spatial

Material

Allegiance

Hierarchical 


\section{Discussion}

The analysis demonstrated how participants used the functional primer of efficiency to guide their decision-making. The choice of where to invest personal resources was based upon the perceived value of specific learning processes and outcomes. Constructing interprofessional groups as markets where knowledge could be traded and bartered resonates with Challis et al.'s (1988) notion of social exchange that emphasises that collaboration is nurtured where self-interest and personal gain are obtainable for the individuals involved. When integrating the professional and the interprofessional, participants clearly nurtured an emergent professional identity, categorising themselves (and others) by their profession. Self-categorisation theory proposes that professional identity compartmentalises, facilitating comparisons with others and that individuals will endeavour to enhance and protect their identities in order to generate self-esteem and status (Turner et al., 1987; Turner, 1999; Hornsey and Hogg, 2002). It predicts discriminatory behaviours that favour and prioritise members of the same group over those from other groups. Comparing professions allowed participants to identify and locate professions vis-à-vis one another, based primarily upon professional competence. In so doing, participants nurtured and protected their own identities and presented an image of competence to others. Professional competence was considered the key indicator of belonging to a professional group, though professional, rather than interprofessional, competence were favoured as learning outcomes to which resources could be devoted. This suggests that "collaborative competence" (Barr, 1998) may not be valued in the same way as more specific professional competencies. 
Participants sought and nurtured an ideal type in identity formation, but reconstructed their identities through interaction and negotiation. Participants also attempted to construct, protect and maintain an image of competence when viewed by others, comparable to Goffman's (1959) seminal work on self-presentation and impression management. The protecting and nurturing of professional identities demonstrated in relative distancing perhaps most closely aligns with Wackerhausen's (2009) examination of micro-level identity formation. Wackerhausen (2009) identifies the importance of the social in forming identities of the self. Participants demonstrated adherence to social behavioural rules associated with their chosen profession. Wackerhausen (2009, p.461, emphasis in original) comments on how this is accomplished through the embodiment of "rules, beliefs and habits" that allows the individual "to be one of our kind". Such embodiment is promoted, too, in the practice setting through social learning that nurtures conformity in the communities of practice (Lave \& Wenger, 1991; Wenger, 1999) of which qualified practitioners become part.

The conditions of relevance, co-presence and a context for meaningful interaction were central to participants' manipulation of distance. These conditions provided a basis with which the professional and the interprofessional could be more fully integrated. The identification of co-presence and a context for interaction in this dataset resonates to some extent with the contact hypothesis developed by Allport (1954). The contact hypothesis is well established in the interprofessional literature for its theoretical relevance (Hean and Dickinson, 2005) and its delineated concepts that make it a useful evaluative tool (Carpenter, 1995; Carpenter and Hewstone, 1996; Barnes et al., 2000). Allport (1954) proposes that tension and hostility 
between groups can be reduced by bringing them together, but asserted that contact alone was insufficient to effect positive change without the conditions of equal status, common goals, co-operation of task, and the support of authorities. These conditions were then expanded by Hewstone and Brown (1986) to include the need for positive expectations, successful joint working outcomes, appreciation of similarities and differences, and a perception of contact as typical. The functional primer of efficiency, though, remained at the forefront of participants' decisionmaking actions in this study. Data were immersed in a discourse of economic efficiency. I contend that such taken-for-granted commitment to the efficient investment of personal resources at the individual level has accompanied broader political developments in health and social care and higher education.

Repertoires of efficiency have underpinned successive health care reforms under the rubric of modernisation (e.g. Department of Health, 1997; 2000; 2003; 2006; 2010). Market competition has been gradually linked with the rhetoric of cooperation and collaboration, insinuating that the rise of IPE and collaborative practice is contingent upon market theories that emphasise self-interest (Adams, 2003; 2005). At the level of the individual, there is greater emphasis on flexibility and transferability of roles and tasks (Cameron, 2000). The performative practitioner is conceived as responsive to external requirements, specified targets and protocols. With it, the notion of professionalism has transformed from an emphasis on situation-specific professional judgement to a willingness to adapt to policy priorities.

In higher education the discourse of efficiency is pervasive, emphasising investment, relevance and buy-in. Forced to base commitments to learning on goals of 
performance, competence and achievement, it is perhaps unsurprising that concepts of efficiency, value and worth were so forthcoming. Interprofessional learning opportunities were welcomed where they were constructed as useful and relevant commodities; exemplifying what Lyotard (1984, p.51) calls the "commodification...of knowledge" that constructs knowledge as "useful, saleable and efficient", optimising skills for flexibility, transferability and profit. Educational policy is written almost exclusively in terms of economic value and market competitiveness (Reich, 2004). Mirroring health care, it has become infused with the rhetoric of choice, reconstructing students as customers seeking educational value for money. Universities have to compete, to "sell" their programmes as products; modules and credits become transferable with no guarantee of internal coherence; and the educator-student relationship turns from a pedagogical one to a contractual one. Some assert that such a transformation is anathematic to the traditional values of academe (Miller, 2010). Shumar (1997, p.31) argues that universities have become "institutionally rearranged based upon a model of capitalist accumulation". Whilst marginalisation of the traditional educator-student relationship may be interpreted as rendering the student an active consumer but a passive learner, Robertson (2000, p.91) considers the potential benefits of the fluidity that commodification delivers in "organisational flexibility and professional academic cross-fertilisation".

\section{Conclusion}

The construction of relative distancing through grounded theorising and discussion of the social processes that emerged from the analysis point towards a recommendation that may possess practical utility in supporting IPE. There is a need to recognise that economic efficiency underpins individual and institutional 
choices. When considering the theoretical foundations of IPE, economic theory has perhaps been neglected by curriculum designers in favour of educational theory and models from social psychology. Taking economic imperatives into account may lead to better understandings of how interprofessional interactions play out. By making IPE relevant and allowing a context for interaction, so collaborative values and interprofessional identities may be nurtured, further integrating the professional and the interprofessional.

\section{Declaration of interest}

The author alone is responsible for the content of the paper.

\section{Acknowledgements}

The author wishes to thank Dr. Peter Martin, Professor Marilyn Hammick and Dr. Mark Francis-Wright for critical feedback on an earlier version of the research presented in this article. 


\section{References}

Adams, A. (2003) The Modernisation of Social Work Practice and Management in England. Eichstatt: ISIS.

Adams, A. (2005) Theorising interprofessionalism. In: Colyer, H., Helme, M. and Jones, I. (eds.) The Theory-Practice Relationship in Interprofessional Education. Occasional Paper No. 7 (p.31-37). London: Higher Education Academy, HSP.

Allport, G. (1954) The Nature of Prejudice. Reading, MA: Addison-Wesley.

Barnes, D., Carpenter, J. and Dickinson, C. (2000) Interprofessional education for community mental health: attitudes to community care and professional stereotypes. Social Work Education; 19, 6: 565-583.

Barr, H. (1998) Competent to collaborate: towards a competency-based model for interprofessional education. Journal of Interprofessional Care; 12, 2: 181-187.

Barr, H. (2002) Interprofessional education: today, yesterday and tomorrow. Occasional Paper No.1. London: The Higher Education Academy, HSP.

Barr, H. and Ross, F. (2006) Mainstreaming interprofessional education in the United Kingdom: a position paper. Journal of Interprofessional Care; 20 (2), 96-104.

Benner, P. (1984) From Novice to Expert: Excellence and Power in Clinical Nursing Practice. Menlo Park, CA: Addison-Wesley Publishing.

Blumer, H. (1969) Symbolic Interactionism: Perspective and Method. Englewood Cliffs, NJ: Prentice-Hall.

Cameron, A. (2000) New role developments in context. In: Humphries, D. and Masterson, A. (eds.) Developing New Clinical Roles. Edinburgh: Churchill Livingstone. 
Carmel, S. (2006) Boundaries obscured and boundaries reinforced: incorporation as a strategy of occupational enhancement for intensive care. Sociology of Health and IIIness; 28 (2), 154-177.

Carpenter, J. (1995) Doctors and nurses: stereotypes and stereotype change in interprofessional education. Journal of Interprofessional Care; 9, 2: 151-161.

Carpenter, J. and Hewstone, M. (1996) Shared learning for doctors and social workers: evaluation of a programme. British Journal of Social Work; 26, 2: 239-257.

Challis, L., Fuller, S., Henwood, M., Klein, R., Polwden, W., Webb, A., Whittingham, P. and Wistow, G. (1988) Joint Approaches to Social Policy. Cambridge: Cambridge University Press.

Charmaz, K. (2006) Constructing Grounded Theory: A Practical Guide Through Qualitative Analysis. Thousand Oaks, CA: Sage.

Clark, P. (2006) What would a theory of interprofessional education look like? Some suggestions for developing a theoretical framework for teamwork training. Journal of Interprofessional Care; 20 (6), 577-589.

Clarke, A. (2005) Situational Analysis: Grounded Theory After the Postmodern Turn. Thousand Oaks, CA: Sage.

D'Eon, M. (2005) A blueprint for interprofessional learning. Journal of Interprofessional Care; 19, supplement 1, 49-59.

Department of Health (1997) The New NHS. London: HMSO.

Department of Health (2000) The NHS Plan. London: HMSO.

Department of Health (2003) The NHS Plan - A Progress Report. London: HMSO.

Department of Health (2006) Our Health, Our Care, Our Say: A New Direction for Community Services. London: HMSO. 
Department of Health (2010) Liberating the NHS: Regulating Health Care Providers. London: HMSO.

Dey, I. (1999) Grounding grounded theory. San Diego: Academic Press.

Freeth, D., Hammick, M., Reeves, S., Koppel, I. and Barr, H. (2005) Effective Interprofessional Education: Development, Delivery and Application. Oxford: Blackwell.

Gilbert, J. and Bainbridge, L. (2003) Canada - interprofessional education and collaboration: theoretical challenges, practical solutions. In Leathard, A. (ed.) Interprofessional Collaboration: From Policy to Practice in Health and Social Care (p.280-296). London: Routledge.

Glaser, B. (1978) Theoretical Sensitivity: Advances in the Methodology of Grounded Theory. Mill Valley, CA: Sociology Press.

Glaser, B. (1998) Doing Grounded Theory: Issues and Discussions. Mill Valley, CA: Sociology Press.

Glaser, B. (2005) The Grounded Theory Perspective III: Theoretical Coding. Mill Valley, CA: Sociology Press.

Glaser, B. G. and Strauss, A. L. (1967) The Discovery of Grounded Theory: Strategies for Qualitative Research. New York: Aldine De Gruyter.

Goffman, E. (1959) The Presentation of Self in Everyday Life. Garden City, NY: Doubleday Anchor.

Hean, S. and Dickinson, C. (2005) The contact hypothesis: an exploration of its further potential in interprofessional education. Journal of Interprofessional Care; 19, 5: 480-491.

Hean, S., Barr, H., Borthwick, A., Carr, E., Craddock, D., Dickenson, C., Hammick, M., Hind, M., Miers, M. and O'Halloran, C. (2008) Evolving IPE Theory for 
Practice: The Outcomes of Discussion from a Seminar Series. Retrieved from http://ihcs.bournemouth.ac.uk/etipe/pdf/s1reflect.pdf.

Hean, S., Craddock, D. and O'Halloran, C. (2009) Learning theories and interprofessional education: a user's guide. Learning in Health and Social Care; 8 (4), 250-262.

Hean, S., Craddock, D. and Hammick, M. (2012) Theoretical insights into interprofessional education: AMEE Guide No. 62. Medical Teacher; 34, e78e101.

Hewstone, M. and Brown, R. (1986) Contact is not enough: an intergroup perspective on the 'contact hypothesis'. In: Hewstone, M. and Brown, R. (eds.) Contact and Conflict in Intergroup Encounters (p.3-44). Oxford: Blackwell.

Holstein, J. and Gubrium, J. (2003) Inside interviewing: new lenses, new concerns. In: Holstein, J. and Gubrium, J. (eds). Inside Interviewing (p.3-31). Thousand Oaks, CA: Sage.

Hornsey, M. and Hogg, M. (2002) The effects of status on subgroup relations. British Journal of Social Psychology; 41, 2: 203-218.

Latour, B. (1987) Science in Action: How to Follow Scientists and Engineers Through Society. Cambridge, MA: Harvard University Press.

Lave, J. and Wenger, E. (1991) Situated Learning: Legitimate Peripheral Participation. Cambridge: University of Cambridge Press.

Lyotard, J.-F. (1984) The Postmodern Condition: A Report on Knowledge. Manchester: Manchester University Press.

Menzies, I. (1970) The Functioning of Social Systems as a Defence Against Anxiety. London: Tavistock Institution of Human Relations. 
Mezirow, J. (1991) Transformative Dimensions of Adult Learning. San Francisco, CA: Jossey-Bass.

Miller, B. (2010) Skills for sale: what is being commodified in higher education? Journal of Further and Higher Education; 34 (2), 199-206.

Reeves, S. (2010) Ideas for the development of the interprofessional field. Journal of Interprofesssional Care; 24 (3), 217-219.

Reeves, S., Suter, E., Goldman, J., Martimianakis, T., Chatalalsingh, C. and Dematteo, D. (2007) A scoping review to identify organisational and educational theories relevant for interprofessional practice and education.

$\begin{array}{ll}\text { Retrieved from } & \text { from }\end{array}$ http://meds.queensu.ca/quipped/assets/ScopingReview IP Theories Dec07. pdf.

Reich, R. (2004) The Destruction of Public Higher Education in America, and How the UK Can Avoid the Same Fate. $2^{\text {nd }}$ Higher Education Policy Institute lecture delivered $25^{\text {th }}$ March 2004.

Robertson, D. (2000) Students as consumers: the individualisation of competitive advantage. In Scott, P. (ed.) Higher Education Reformed. London: Falmer Press.

Shumar, W. (1997) College for Sale: A Critique of the Commodification of Higher Education. London: Falmer Press.

Slater, D. and Tonkiss, F. (2001) Market Society. Cambridge: Polity Press.

Spradley, J. (1980) Participant Observation. New York: Holt, Rinehart and Winston.

Timmermans, S. and Tavory, I. (2007) Advancing ethnographic research through grounded theory practice. In Bryant, A. and Charmaz, K. (eds.) The Sage Handbook of Grounded Theory (p.493-512). London: Sage. 
Turner, J. (1999) Some current issues in research on social identity and selfcategorisation theories. In Ellemers, N., Spears, R. and Doosje, B. (eds.) Social Identity. Oxford: Blackwell.

Turner, J., Hogg, M., Oakes, P., Reicher, S. and Wetherall, M. (1987) Rediscovering the Social Group: A Self-Categorisation Theory. Oxford: Blackwell.

Wackerhausen, S. (2009) Collaboration, professional identity and reflection across boundaries. Journal of Interprofessional Care; 23 (5), 455-473.

Wenger, E. (1999) Communities of Practice. Learning, Meaning and Identity. Cambridge: Cambridge University Press.

World Health Organisation (2010) Framework for Action on Interprofessional Education and Collaborative Practice. Geneva: WHO.

World Health Organisation Study Group (2010) Interprofessional Education and Collaborative Practice Glossary. Retrieved on $25^{\text {th }}$ July 2010 from http://cihc. wikispaces.com/Interprofessional+Glossary.

Zimmerman, D. and Wieder, D. (1977) The diary-interview method. Urban Life; 5, 479-498. 